\title{
Infant Industry Argument, Protection and Manufacturing Industries of Pakistan
}

\begin{abstract}
A. R. Kemai*
The Infant Industry Argument is tested against the experience of Pakistan's manufacturing industries. The learning coefficients are estimated by fitting both the Cobb-Douglas and the C.E.S. production functions. The learning coefficients estimated for Pakistan corroborate the Infant Industry Argument. Higher learning coefficients in the case of Pakistan than those observed in other countries underline the fact that the industries had cost disadvantages in the initial stages of their establishment.
\end{abstract}

The Infant Industry Argument is perhaps the most important theoretical argument for justifying protection to the domestic manufacturing industries in the initial stages of their establishment. It is argued that because of poor infrastructure and inexperienced labourers and entrepreneurs the cost of domestic production exceeds the cost of imported manufactured goods and as such domestic manufacturers cannot compete with foreign producers in the domestic market. Over the long-run, however, once the necessary infrastructure gets developed, labourers and entrepreneurs will hopefully acquire the necessary experience, enabling the domestic producers to become fully competitive in the world market.

The record of the late Sixties and early Seventies suggests that protection does not enable a developing country, like Pakistan, to overcome the initial cost disadvantages but rather leads to a persistence of inefficiencies. It is argued that, in the presence of sufficiently higher profits ensured by protection, producers do not make enough effort to find the lowest cost techniques of production and organization. Therefore, one would not expect any significant improvement in the productivity of the protected industries. It may be noted that in contrast to this view, those who favour protection to manufacturing industries argue that protection provides a breathing space to the domestic producers to overcome the initial cost disadvantages. Therefore, as regards the impact of protection on the level of efficiency, we have two opposing hypothesis, viz. (1) the protectionist policies have resulted in the persistence of ineffciencies, and (2) the protectionist policies are responsible for a reduction in inefficiencies in the manufacturing industries of Pakistan.

*The author is a Senior Research Economist at the Pakistan Institute of Development Economics. Islamabad. The paper is a part of $\mathrm{Ph}$. D. dissertation submitted to the University of Manchester. He is deeply indebted to his supervisors, Mr. P. J. Devine and Dr. C. H. Kirkpatrick for their useful comments on an earlier draft of the paper. 
There has hardly been any study examining the two hypotheses; the only exception is a Tariff Commission's study, the conclusions of which are summarised in Islam [5, p. 224]. The study found that the cost ratios ${ }^{1}$ declined by 25 percent to 60 percent in the case of sixteen products and by $5-24$ percent in the case of forty other products included in the sample. The study highlights a marked improvement in productivity over time. However, the commodities included in the sample formed a very small proportion of the total manufacturing production. Most of the important industries, like textiles, sugar, vegetable ghee, cement, tobacco, etc., which form a bulk of the manufacturing production, were excluded from the sample. The Commission's study cannot, therefore, be taken as representative of the manufacturing sector as a whole.

If the hypothesis that protection promotes inefficiencies in production is true, then one does not expect any significant improvements in productivity over time. However, the Infant Industry Argument, which promises an eventual outward shift of the production possibility frontier will require Learning-by-Doing to be a major source of increase in productivity.

The Learning-by-Doing hypothesis was formally put forth in 1962 by Arrow [1]. He argued that, in the presence of learning, private investment falls short of the socially optimum level of investment and, therefore, recommended a subsidising of the social investment. ${ }^{2}$

It may be pointed out that an earlier study [9] showed that, in Pakistan, productivity in the manufacturing sector increased very rapidly: in fact, at a rate exceeding five percent. It follows that the hypothesis that protection promotes inefficiencies in production is not borne out by the experience of the manufacturing industries of Pakistan.

The present study seeks to determine learning as a factor contributing to an increase in productivity over the period $1959-1960$ to $1969-1970$. The study is divided into four sections. The first section summarises the forms of the learning hypothesis while the second section discusses specifications of different hypothesis and the estimation procedures. The results of the empirical exercise are reported in the third section. The final section highlights the major conclusions and policy implications. The data problems have been discussed in the Appendix.

\section{THE HYPOTHESIS AND DIFFERENT SPECIFICATIONS}

Fellner [4, pp. 121, 124] has distinguished between two concepts of learning: (i) 'experience is acquired by doing more than one has so far done,

${ }^{1}$ Cost ratios employed by the Tariff Commission are costs of production including normal return to capital divided by the c.i.f. prices.

Empirically, the learning hypothesis dates back to Wright [20] in 1936 when he discovered that in the airframe industry the cost of production declined as the production because of learning regardless of the length of time it takes to do more'; and (ii) 'experience is acquired by doing it longer regardless of the steepness of the rise in the cumulated output'. The latter concept is not very interesting because it disregards the effect of an increase in production on learning. It is the former concept of learning with which we shall be concerned in this paper.

In the specification of the learning effects in the production function, we have followed the Sheshinsky approach [17] rather than that of Arrow [1]. The main difference between the models proposed by Arrow and Sheshinsky is that while Arrow uses a vintage model and assumes fixed coefficients, Sheshinsky allows for disembodied technical change and for substitution between factor inputs. Also, as shown by Bardhan [2], Sheshinsky's approach simplifies estimation and retains the essence of the argument.

In order to estimate the learning coefficients, two alternative indices of experience have been suggested by Arrow, Sheshinsky and others. The two indices are cumulated gross investment and cumulated output. Both the indices give rise to irreversible economies that characterise dynamic learning processes. Investment, being capable of changing the "environment" in which production takes place with respect to the changes in the existing technology, provides continual stimuli for the learning process to take place. Furthermore, cumulated output, even in the absence of investment, stimulates and generates additional learning.

However, one cannot choose, on an a priori basis, between the two indices as more appropriate. It must be established empirically. It may also be noted that it is the capability of gross investment to change the environment which leads to learning. It follows that, as pointed out by David [3], if the increase in productivity comes through an improvement in the design of the machinery, then the protection may be granted to 'machine-building' and not to the 'machine-using' industries. However, it is not possible to discriminate statistically between the two opposing views regarding the impact of cumulated gross investment on learning, i.e. whether the production increases are due to changes in the environment in which production takes place, or to an improvement in the design of the machinery. However, if the learning factor is explained by a cumulated output, conclusions regarding the subsidisation or protection of the manufacturing sector seem to be straightforward.

\section{SPECIFICATION OF DIFFERENT HYPOTHESES AND PROBLEMS} OF ESTIMATION

Let $\mathrm{G}$ be an index of experience so that the neoclassical $\mathrm{g}$ production function can be written as: 
where

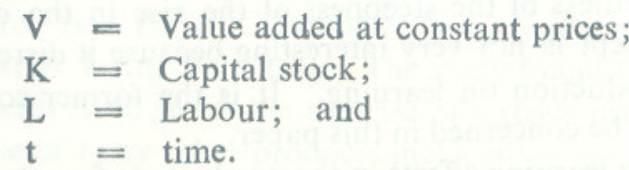

In the logarithmic form, we may write (1) as

$$
\text { Ln } V=\operatorname{Ln} A(G, t)+L n F(K, L)
$$

Differentiating with respect to time, we get:

$$
\begin{aligned}
& \frac{d V / d t}{V}=\left[\frac{(\partial A / \partial G)}{A}\right] \frac{d G / d t}{G}+\frac{d A / d t}{A}+\left[\frac{\partial F}{\partial K} \cdot \frac{K}{F}\right] \frac{d K / d t}{K} \\
& +\left[\frac{\partial F}{\partial L} \cdot \frac{L}{F}\right] \frac{d L / d t}{L}
\end{aligned}
$$

In contrast to the dependence of the residual only on time, equation (3) shows that the residual is composed of two parts, one being dependent on time and the other on experience.

By specifying $A_{t}$ as an exponential function, we write:

$$
A_{t}=A_{0} e^{\lambda t} G^{\gamma}
$$

Two special cases of equation (4) may be noted. The first case is in which $\gamma=0$, i.e. the growth of productivity is not explained by experience and the estimation is carried out as if the productivity increase results from a disembodied technical change. The second case is that in which $\lambda=0$, i.e. learning is the only source of productivity gains. In general, though the two effects operate simultaneously, their joint estimation is almost impossible because of the multicollinearity between the time factor and the learning,coefficient. Hence, it is on the two special cases that the estimation effort should focus.

The Cobb-Douglas production function incorporating increases in productivity arising out of both learning and the technical progress may be written as:

$$
V=A_{0}\left[e^{\lambda t} G^{\gamma}\right]\left[\begin{array}{ll}
\alpha & L^{\beta}
\end{array}\right] \cdots
$$

which, with constant returns to scale, reduces to:

$$
y=A_{0}\left[e^{\lambda . t} G^{\gamma}\right] k^{1-\alpha}
$$

where $y=V / L$ and $k=K / L$

Equations (5) and (6) may be rewritten in the logarithmic form as equations (7) and (8) given below:

$$
\begin{aligned}
& \text { Ln } V=\operatorname{Ln} A_{0}+\lambda t+\gamma \operatorname{LnG}+\alpha \operatorname{Ln} L+\beta \operatorname{LnK} \quad \ldots \\
& \text { Ln } y=\operatorname{Ln} A_{0}+\lambda t+\gamma \operatorname{Ln} G+(1-\alpha) \operatorname{Ln} k
\end{aligned}
$$

These two equations may be estimated by the method of the ordinary least squares (O.L.S.).

If the C.E.S. production function is specified instead of the CobbDouglas production function, we may write it as:

$$
V=A_{0} e^{\lambda t} \quad G\left[\begin{array}{cc}
-p & -p L^{-v}+(1-\delta) K^{-v / \rho}
\end{array}\right]^{-}
$$

After linearising the C.E.S. production function, using Kmenta's approximation [10], one derives the following two relations for the variable and constant returas to scale:

$$
\begin{aligned}
& \mathrm{Ln} \quad \mathrm{V}=\mathrm{Ln} \mathrm{A}_{0}+\lambda \mathrm{t}+\gamma \operatorname{Ln} \mathrm{G}+\mathrm{v} \delta \mathrm{Ln} \mathrm{L}+\mathrm{v}(1-\delta) \mathrm{Ln} \mathrm{K} \\
& -\frac{1}{2} \text { v } \rho \delta(1-\delta) \quad[\operatorname{Ln}(\mathrm{K} / \mathrm{L})]^{2} \quad \ldots \\
& \mathrm{LI} \quad y=\operatorname{Ln} A_{0}+\lambda t+\gamma \operatorname{LnG}+(1-\delta) \operatorname{Ln~k} \\
& -\frac{1}{2} \rho \delta(1-\delta)(\operatorname{Ln~k})^{2}
\end{aligned}
$$

As said eariier, the simultaneous estimation of the coefficients of time and experience becomes almost impossible because the two variables are collinear. The situation is even worse when the returns to scale are not constrained. Therefore, we shall first report the results obtained by setting $\lambda=0$ and assuming constant returns to scale. These assumptions are then relaxed one by one and the estimates are obtained accordingly.

\section{RESULTS}

We have estimated learning coefficients by fitting both the Cobb-Douglas and the C.E.S. production functions for the manufacturing industries of Pakistan. The cumulated output and gross investment have been used alternatively as the indices of experience to estimate the learning coefficient.

\section{Constant Refurns to Scale}

The learning coefficients, estimated by assuming constant returns to scale, and leaving time out of the set of the explanatory variables, are reported in Table 1. These estimates suggest that the Learning-by-Doing hypothesis is supported by the experience of the manufacturing industries of Pakistan. When the cumulated output is used as an index of experience and the CobbDouglas production function is specified, the learning coefficients turn out to be positive and statistically significant in twelve out of sixteen industries. In two more industries the coefficient is positive but is not statistically significant If the C.E.S. production function is specified instead of the Cobb-Douglas form, the learning coefficient is positive in thirteen industries and statistically significant in ten. 
Alternatively, when the cumulated investment is taken as an index of experience and the Cobb-Douglas production function is specified, the learning coefficient is positive in fourteen industries and significant in nine of them. On the other hand, when the C.E.S. production function is specified, the learning coefficient is positive in twelve industries and significant in eight of them. For the manufacturing sector as a whole, the learning coefficient is positive and significant whether the Cobb-Douglas or C.E.S. production function is specified or the cumulated output or cumulated gross investment is specified. These results empirically substantiate the Learning-by-Doing hypothesis, suggesting that the cumulated output may, after all, be a better explanatory variable than the cumulated investment. A comparison of the coefficients of determination (Table 2) establishes the superiority of cumulated output over cumulated gross investment as an explanatory variable.

\section{Variable Returns to Scale}

Allowing for variable returns to scale leads to serious problems of multicollinearity in the estimation of the learning coefficients along with the other coefficients causing both the coefficients of labour and capital and learning coefficients to behave erratically. The learning coefficients are reported in Table 3.

Table 3 shows that when the assumption of constant returns to scale is relaxed, the learning coefficients get inflated in most cases while they turn negative in other cases. Correspondingly, the coefficients of labour and capital (not shown in Table 3) are either very low or negative or, in some cases, even much too high. Therefore, even though the learning coefficients for some of the manufacturing industries and the manufacturing sector as a whole are significant not much reliance can be placed on these estimates as they suffer from multicollinearity. Similarly, when both the time factor and the learning coefficient are included in the regression equation, the problem of multicollinearity gets serious.

Because the multicollinearity problem does not allow an estimation of the coefficients of time and learning, they can only be estimated by fitting separate relations for the estimation of each coefficient. However, one is then faced with the problem of deciding between the Learning-by-Doing and some other forms of technical change as the decisive factor explaining the increase in productivity. There are two ways in which one can choose between the two specifications. Firstly, the production functions may be estimated either by including only time as one of the explanatory variable while omitting the learning variable, or by including only the learning variable as one of the explanatory variables and omitting the time variable. The coefficients of determination can then be compared. The specification yielding the higher values of the coefficients of determination will then be preferred. Secondly, both the variables, viz. learning and time, can be included in the same specified function and one can then observe which of the two coefficients 
Table 2

Comparison of the Coefficients of Determination $\left(R^{2}\right)$

\begin{tabular}{|c|c|c|c|c|c|}
\hline & \multirow[b]{2}{*}{ Industry } & \multicolumn{2}{|c|}{ Cobb-Douglas } & \multicolumn{2}{|c|}{ C.E.S. } \\
\hline & & $\begin{array}{l}\text { Cumulated in- } \\
\text { vestment as an } \\
\text { Index of learn- } \\
\text { ing }\end{array}$ & $\begin{array}{l}\text { Cumulated Out- } \\
\text { put as an Index } \\
\text { of learning }\end{array}$ & $\begin{array}{c}\text { Cumulated in- } \\
\text { vestment as an } \\
\text { Index of learn- } \\
\text { ing }\end{array}$ & $\begin{array}{l}\text { Cumulated Out- } \\
\text { put as an Index } \\
\text { of learning }\end{array}$ \\
\hline $\begin{array}{c}1 . \\
2 . \\
3 . \\
4 . \\
5 . \\
6 . \\
7 . \\
8 . \\
9 . \\
10 . \\
11 . \\
12 . \\
13 . \\
14 . \\
15 . \\
16 .\end{array}$ & $\begin{array}{l}\text { Food Processing Industries } \\
\text { Tobacco Manufacturing Industries } \\
\text { Manufacturing of Textiles } \\
\text { Footwear and other Wearing Apparel } \\
\text { Paper and Paper Products } \\
\text { Printing and Publishing } \\
\text { Leather and Leather Products } \\
\text { Rubber and Rubber Products } \\
\text { Chemicals and Chemicals Products } \\
\text { Non-metallic Mineral Products } \\
\text { Basic Metals Industries } \\
\text { Manufacturing of Metal Products } \\
\text { Non-electrical Machinery } \\
\text { Electrical Machinery } \\
\text { Transport Equipment } \\
\text { Miscellaneous Industries } \\
\text { Total: Manufacturing Sector }\end{array}$ & $\begin{array}{l}.67 \\
.08 \\
.59 \\
.02 \\
.90 \\
.82 \\
.19 \\
.84 \\
.24 \\
.17 \\
.59 \\
.58 \\
.72 \\
.79 \\
.49 \\
.76 \\
.84\end{array}$ & $\begin{array}{l}.73 \\
.24 \\
.64 \\
.04 \\
.81 \\
.85 \\
.36 \\
.84 \\
.24 \\
.37 \\
.69 \\
.57 \\
.59 \\
.77 \\
.43 \\
.74 \\
.88\end{array}$ & $\begin{array}{l}.70 \\
.19 \\
.80 \\
.03 \\
.90 \\
.85 \\
.75 \\
.84 \\
.36 \\
.24 \\
.64 \\
.83 \\
.87 \\
.72 \\
.51 \\
.78 \\
.89\end{array}$ & $\begin{array}{l}.76 \\
.41 \\
.82 \\
.04 \\
.81 \\
.86 \\
.77 \\
.84 \\
.33 \\
.40 \\
.69 \\
.81 \\
.84 \\
.59 \\
.44 \\
.76 \\
.92\end{array}$ \\
\hline
\end{tabular}

These coefficients of determination are for equations (6) and (11) the results of which are reported in Table 1.

Table 3

Learning Coefficients: Variable Returns to Scale

Industry

Cumulated Gross Investment as Cumulated Output as an

an Index of learning

\begin{tabular}{cccc}
\hline Cobb-Douglas & C.E.S. & Cobb-Douglas & C.E.S. \\
\hline $5.0623^{*}$ & $5.0752^{*}$ & $.8550^{*}$ & $.8652^{*}$ \\
-7.9271 & -2.5860 & $1.2538^{*}$ & -.1592 \\
$4.8775^{*}$ & $5.2629^{*}$ & $1.2655^{*}$ & $1.2644^{*}$ \\
4.1184 & 4.7207 & .6806 & .7102 \\
.4240 & .8613 & $.3868^{*}$ & $.3930^{*}$ \\
.6700 & 1.4109 & .1111 & .2808 \\
1.2971 & -18.2948 & .5206 & -.3519 \\
2.0689 & 2.0333 & .5322 & .3560 \\
-.4824 & -.2759 & -.0555 & .0041 \\
-.1473 & -.0651 & $-.6382^{*}$ & $-.0708^{*}$ \\
$9.2311^{*}$ & 9.5242 & $1.1267^{*}$ & $1.2633^{*}$ \\
.0154 & -.1356 & .0185 & -.0324 \\
-.5801 & $-1.1339^{*}$ & -.0531 & -.1602 \\
-1.8840 & $-1.8484^{*}$ & -.2545 & -.1899 \\
-.6233 & -.2918 & -.2317 & -.1680 \\
$3.1239^{*}$ & $3.0515^{*}$ & $.7013^{*}$ & $.6775^{*}$ \\
$2.1020^{*}$ & $1.8144^{*}$ & $.5944^{*}$ & $.5274 *$ \\
\hline
\end{tabular}

These estimates are obtained through equations (5) and (10).

-Indicates significance at 5 percent level. 
is forced to insignificance and/or the wrong sign. In Table 4 the coefficients of determination are compared, while in Table 5 the coefficients of time and learning, estimated simultaneously, are reported.

Table 4 shows that in the case of most of the industries, an inclusion of the learning coefficients instead of the time ceofficient yields a higher coefficient of determination. However, the difference is quite small. We, therefore, turn to the second test.

It may be seen from Table 5 that when both time and learning are included in the function the learning coefficients remain positive, though turning insignificant in some cases, while the coefficients of time turn negative in most cases. Both the tests suggest that the inclusion of Learning-by-Doing is the better specification. ${ }^{3}$ Therefore, we may conclude that Learning-by Doing rather than some other technical change explains the increase in productivity.

\section{Inter-Country Comparison}

It is interesting to compare the learning coefficients estimated here with those obtained for other countries. In Table 6 they are compared with those for Nigeria, U.S.A. and some other countries. ${ }^{4}$ Thomas [19] reports learning coefficients for Nigeria estimated by using cumulated gross investment as the index of learning. Sheshinsky [17] reports learning coefficients for the manufacturing industries of the U.S.A. and other countries obtained by using both cumulated gross investment and cumulated output to represent Learning-byDoing. The comparison is possible in the case of only a limited number of the industries because of the different industries covered in the three studies. Tables 6 and 7 compare respectively the coefficients obtained by using cumulated gross investment as an index of experience and those yielded when cumulated output is used as an index of experience.

These comparisons reveal that the coefficients of learning of Pakistan's manufacturing industries are a little higher than those for the manufacturing industries of the U.S.A. and some other countries. However, in a number of industries they are not very different. The same picture emerges whether comparison is made by taking cumulated output or cumulated gross investment as an index of learning.

It can be argued that the learning coefficients would be higher if industries are established without adequate preparations. This is plausible because Pakistan started from almost a scratch in most of the industries, with the entrepreneurs and labourers having no experience of the manufacturing industries.

The results underline the importance of Learning-by-Doing as a source of increases in productivity. In order to see the extent to which learning explains

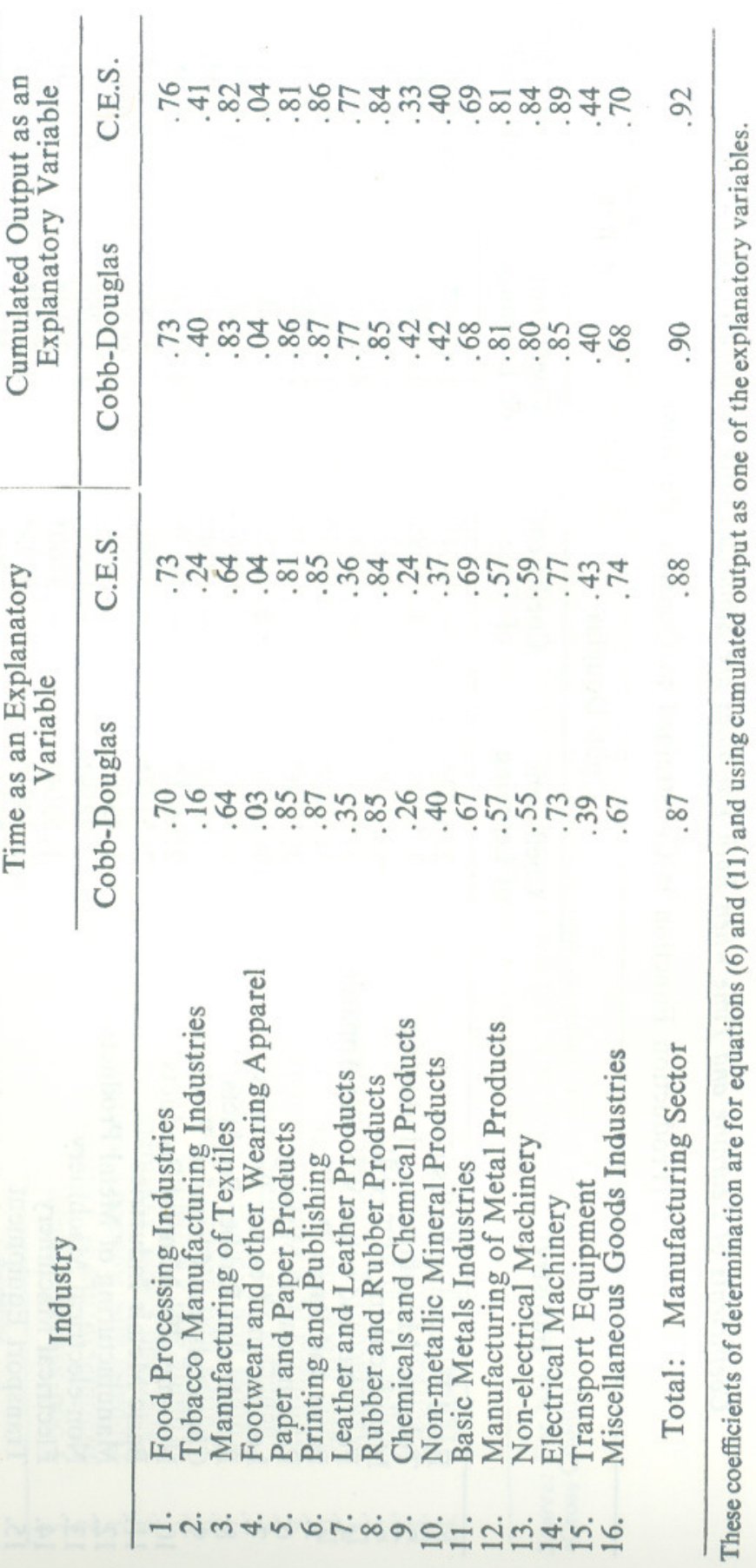
criterion of which of the variables forced the other to insignificance or wrong signs, conclude

that the specification incorporating learning was better than the one incorporating trend.
"Learning coefficients were available only for these countries.

.


Table 5

Coefficients of Learning and Time when Both Variables are Simultaneously Included in the Function

(Production Function is Constrained to Constant Returns)

\begin{tabular}{|c|c|c|c|c|c|}
\hline \multirow{2}{*}{ 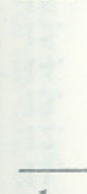 } & \multirow{2}{*}{ Industry } & \multicolumn{2}{|c|}{ Cobb-Douglas } & \multicolumn{2}{|c|}{ C.E.S. } \\
\hline & & $\begin{array}{l}\text { Coefficient } \\
\text { of Learning }\end{array}$ & $\begin{array}{l}\text { Coefficient } \\
\text { of Time }\end{array}$ & $\begin{array}{l}\text { Coefficient } \\
\text { of Learning }\end{array}$ & $\begin{array}{l}\text { Coefficient } \\
\text { of Time }\end{array}$ \\
\hline $\begin{array}{l}1 . \\
2 . \\
3 . \\
4 . \\
5 . \\
6 . \\
7 . \\
8 . \\
9 . \\
10 . \\
11 . \\
12 . \\
13 . \\
14 . \\
15 . \\
16 .\end{array}$ & $\begin{array}{l}\text { Food Processing Industries } \\
\text { Tobacco Manufacturing Industries } \\
\text { Manufacturing of Textiles } \\
\text { Footwear and other Wearing Apparel } \\
\text { Paper and Paper Products } \\
\text { Printing and Publishing } \\
\text { Leather and Leather Products } \\
\text { Rubber and Rubber Products } \\
\text { Chemicals and Chemical Products } \\
\text { Non-metallic Mineral Products } \\
\text { Basic Metals Industries } \\
\text { Manufacturing of Metal Products } \\
\text { Non-electrical Machinery } \\
\text { Electrical Machinery } \\
\text { Transport Equipment } \\
\text { Miscellaneous Goods Industries }\end{array}$ & $\begin{array}{c}2.6463^{*} \\
7.5968 \\
-.5970 \\
3.9501 \\
1.3402^{*} \\
-2.1906^{*} \\
10.1467 \\
-.4179^{*} \\
.8448^{*} \\
2.9631^{*} \\
2.5377^{*} \\
-1.4345^{*} \\
.7259^{*} \\
1.5364^{*} \\
3.1401^{*} \\
1.2628\end{array}$ & $\begin{array}{c}-.3804^{*} \\
-1.3669 \\
.0542 \\
-.6528 \\
-.4204^{*} \\
.5203^{*} \\
-1.9635 \\
.1996 \\
-.1924^{*} \\
-.4942^{*} \\
-.3590 \\
.2192 \\
-.1574 \\
-.3700^{*} \\
-.6093^{*} \\
-.1204\end{array}$ & $\begin{array}{c}2.6060^{*} \\
3.0328 \\
-.8583 \\
4.6845 \\
1.3561^{*} \\
-2.8597^{*} \\
.7093 \\
-.3641 \\
.8959^{*} \\
4.5625^{*} \\
2.4766 \\
-.6885 \\
1.3826^{*} \\
.7418^{*} \\
3.3732^{*} \\
1.4546\end{array}$ & $\begin{array}{l}-.3741^{*} \\
-.3009 \\
.1748 \\
-.7802 \\
-.4257^{*} \\
. .6579^{*} \\
-.1061 \\
-.1914 \\
-.2004^{*} \\
-.7568^{*} \\
-.3489 \\
. .0869 \\
-.3266^{*} \\
-.1601^{*} \\
-.6412^{*} \\
-.1619\end{array}$ \\
\hline & Total: Manufacturing Sector & $.3328 *$ & -.0091 & .4663 & -.0281 \\
\hline
\end{tabular}

Index of learning is the cumulated output.

These estimates are obtained through equations (6) and (11) keeping both time and an index of experience in the set of explanatory variables.

Table 6

The Learning Coefficient in Manufacturing Industries of Pakistan and Other Countries (Cumulated Gross Investment as an Index of Learning)

\begin{tabular}{|c|c|c|c|c|c|}
\hline & Industry & Pakistan & Nigeria & U.S.A. & Cross Countrya \\
\hline $\begin{array}{l}1 . \\
2 . \\
3 . \\
4 . \\
5 . \\
6 . \\
7 . \\
8 . \\
9 . \\
10 . \\
11 . \\
12 . \\
13 . \\
14 .\end{array}$ & $\begin{array}{l}\text { Food Manufacturing } \\
\text { Manufacturing of Textiles } \\
\text { Apparel and Related Products } \\
\text { Paper and Paper Products } \\
\text { Printing and Publishing } \\
\text { Leather and Leather Products } \\
\text { Rubber and Rubber Products } \\
\text { Chemicals and Chemical Products } \\
\text { Non-metallic Mineral Products } \\
\text { Basic Metal Industries. } \\
\text { Manufacturing of Metal Products } \\
\text { Non-electrical Machinery } \\
\text { Electrical Machinery } \\
\text { Transport Equipment }\end{array}$ & $\begin{array}{l}.2120^{*} \\
.5551^{*} \\
.0452^{*} \\
-.4451^{*} \\
.4411^{*} \\
.1849^{*} \\
.8677^{*} \\
.2107 \\
-.8007 \\
.9800^{*} \\
-.1043 \\
.1460^{*} \\
.3502^{*} \\
.7879^{*}\end{array}$ & $\begin{array}{c}-\overline{1.266} \\
.169^{*} \\
.767 \\
\overline{.822 *} \\
-.016 \\
\overline{-} \\
\overline{-} \\
1.276 \\
\overline{.553 *} \\
.530\end{array}$ & $\begin{array}{l}.171 \\
.212^{*} \\
.057 \\
.315^{*} \\
.213 \\
.217 \\
.151 \\
.044 \\
.012 \\
.289 \\
.050 \\
.100^{*} \\
.379^{*} \\
.130^{*}\end{array}$ & $\begin{array}{l}.2048^{*} \\
.3293^{*} \\
\overline{4256^{*}} \\
\overline{-}{ }^{*} \\
.3293^{*} \\
.2665^{*} \\
.4016^{*} \\
.5707^{*} \\
\overline{-} \\
.2398^{*} \\
.2396^{*}\end{array}$ \\
\hline
\end{tabular}

Source: For Nigeria, Thomas [19], for U.S.A. and Cross Country, Sheshinsky [17] and for Pakistan, Table 1. aCross Country regression is based on data taken for different countries, but Sheshinsky does not list them. 


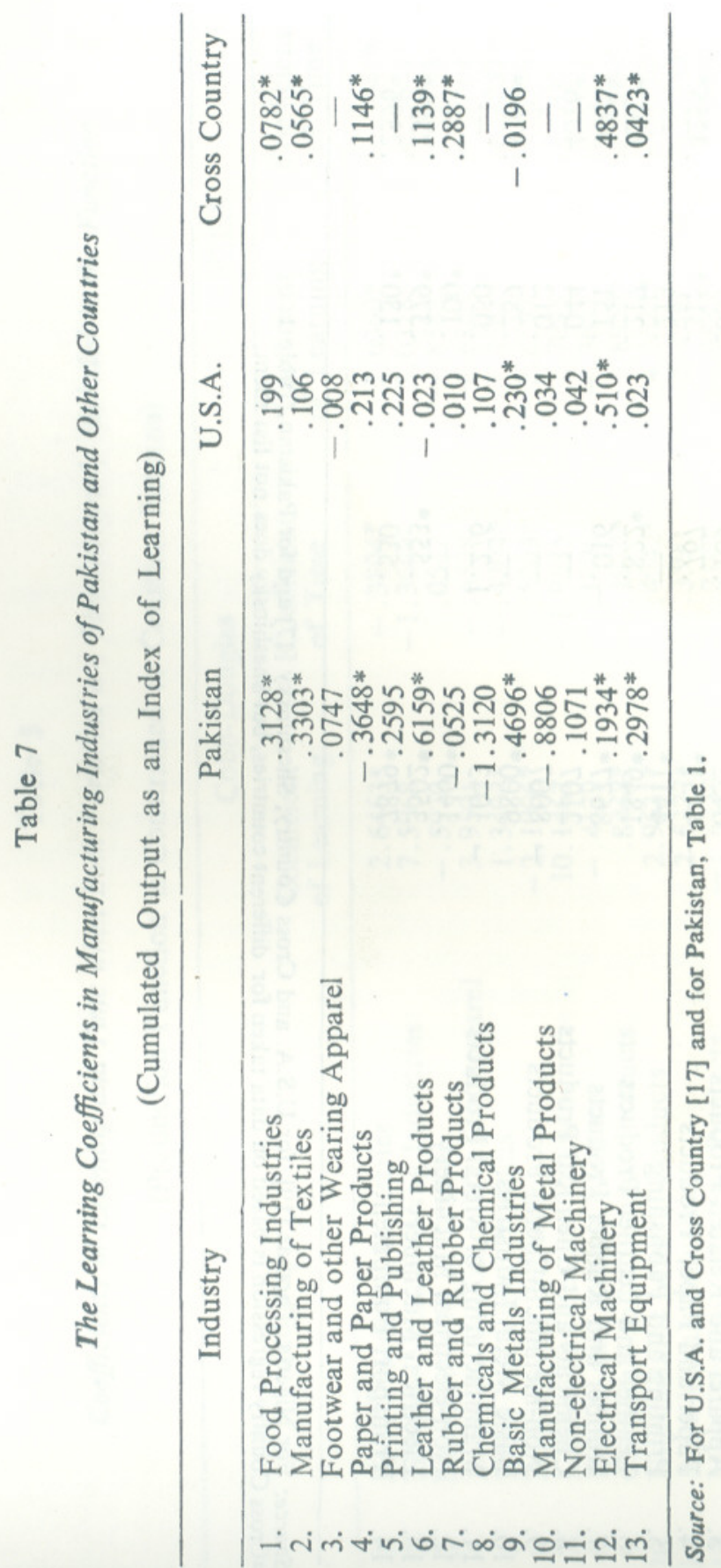

the "residual", we have reported the growth rates of productivity explained by learning in Table 8.

Table 8 shows the impact of learning on the growth rates of productivity to be very similar whether cumulated gross investment or cumulated output is used as an index of learning. For the manufacturing sector as a whole and in almost all industries, learning accounts for $80-85$ percent of the residual. The results also suggest that if the learning hypothesis is accepted, then other types of technical changes have been relatively unimportant in the manufacturing industries of Pakistan.

\section{POLICY IMPLICATIONS}

The foregoing analysis clearly brings out Learning-by-Doing to be the most important source of the rapid increase in the productivity of the manufacturing industries in Pakistan. It has resulted in an outward shift of the production possibility frontier. Combined with the findings of another study [9] that by the end of the Sixties most of Pakistan's large-scale manufacturing industries could compete in the international markets, ${ }^{5}$ one may conclude that the protection has, by and large, been beneficial to the growth of the manufacturing industries, by allowing them to overcome the initial cost disadvantages.

However, the theory of optimal intervention in the presence of the various distortions outlined in various studies, e.g. Johnson [7], Naqvi [12] and others, indicates clearly that the optimal form of government intervention is to direct tax-cum-subsidy at the source of distortion. Applying this theory to a study of Pakistan's experience, it follows that the performance could have been even better, had the learning process been directly subsidised and the effective rates of protection kept lower. This may give the impression that the policy of protecting manufacturing activity was sub-optimal.

However, such an impression needs to be properly qualified. It stands to reason that the learning factor, as an absolute contributory factor to productivity growth may not have been as important as the present study seems to imply, for the higher learning coefficients observed in Pakistan may have been due to the extremely narrow skill base, from where the industrialization process took off in the early Fifties. Furthermore, protection may itself have reinforced the learning process. However, this observation does not vitiate the general conclusion, reinforced by the Pareto optimality considerations, that excessive protection rates observed in Pakistan may have been counterproductive. A sensible policy recommendation flowing from these considerations appears to be that in general the protection rates should be given at rates which roughly account for the cost disadvantage of the new industries, minus the learning factor, which should instead be directly subsidised.

${ }^{5} \mathrm{High}$ rates of protection (subsidy to exports) and lack of inefficiency may look contradictory. They are not because high rates of protection were mainly employed to increase the frecause of a very drastic fall in the 
A. R. Kemal

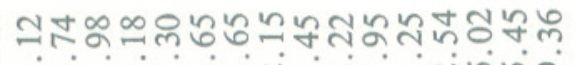

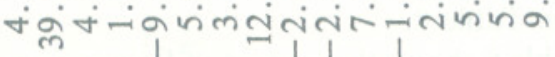

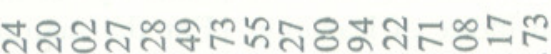

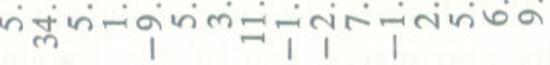

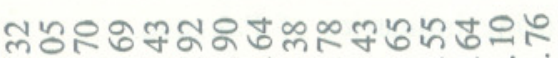
mंत्रिं n :

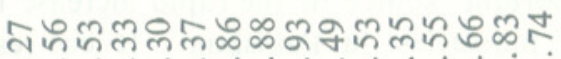

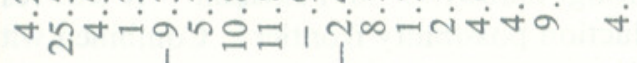

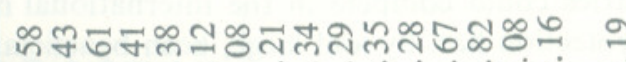

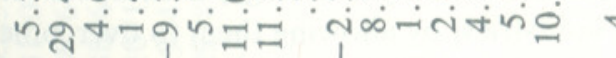

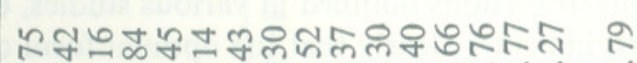
mót

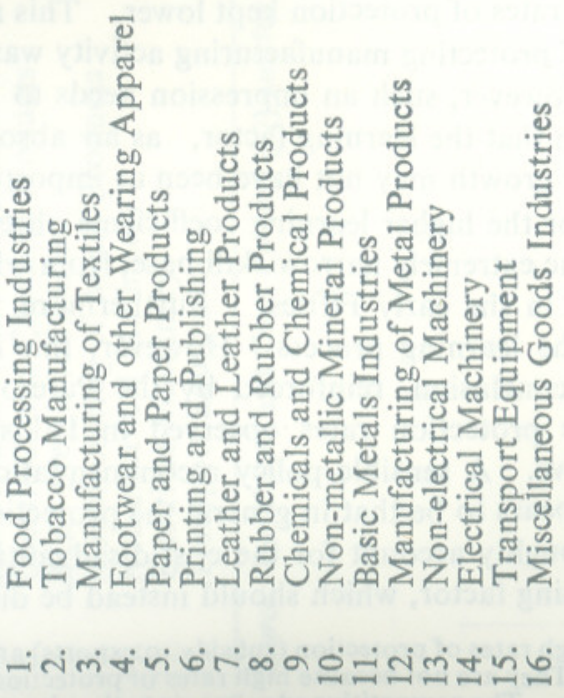

\section{CONCLUSIONS}

The Learning-by-Doing hypothesis seems to be supported by the experience of most of the manufacturing industries in Pakistan. The learning coefficient is positive and significant in twelve out of sixteen industries and in the manufacturing sector as a whole.

Although both cumulated investment and cumulated output yield positive and significant learning coefficients in most of the industries, cumulated output seems to be the better explanatory variable because the coefficient of determination is higher for the function incorporating cumulated output. This lends support to the Infant Industry Argument.

In general, multicollinearity prevents a simultaneous estimation of either the learning coefficients and returns to scale, or learning coefficients and time trends. The function including learning rather than time has the higher coefficient of determination, and the inclusion of both time and experience in the same function leaves the coefficient of learning positive and significant in most cases but forces the coefficient of time to negative values. The Learning-byDoing hypothesis is, therefore, empirically established. The 'learning' factor explains more than 80 percent of the 'residual' in almost all the industries, implying that the other factors were responsible for no more than a one-half percent increase in productivity. Therefore, it may be concluded that protection enables domestic producers and labourers to acquire the necessary skills, which over time tends to offset the cost disadvantages.

It may be pointed out that by the end of the Sixties, most industries were able to compete successfully with imports. However, it must be emphasized that the observed high learning coefficients do not necessarily mean that higher protection rates have no adverse effects on the levels of efficiency. In fact, inefficient industries have been shown to be positively related with the rates of protection [9]. Hence, while protection does enable the acquisition of skills, the high rates of protection may reduce the incentive to improve production skills. Hence, on the margin, protection rates should be set so as to offset the cost disadvantages arising from the absence of the learning factor in the initial stages of industrialization. 


\section{DATA PROBLEMS}

In order to estimate the learning coefficients, one requires data not only on the current inputs and outputs, but also on the cumulated output and investment. Data regarding value added, capital and labour are obtained from Kemal [9]. As mentioned in the second section, experience is measured by two indices, viz. cumulated gross investment and cumulated output. Cumulated gross investment could have been arrived at very easily, had the investment data been available for all the years starting from 1949-1950 up to 1969-1970. However, investment data for the years prior to 1959-1960 are not available, although investment indices are available. Therefore, cumulated gross investment up to $1959-1960$ is obtained by using the following formula:

$$
\left(\sum_{i=1}^{t} I_{i}{ }^{\prime}\right) /\left[\sum_{i=1}^{t}\left(\prod_{j=i}^{t}\left(1-d_{j}\right)\right) I_{i}{ }^{\prime}\right] K_{1959-60}
$$

where $d_{j} \quad$ is the depreciation rate;

$\mathbf{I}_{i}{ }^{\prime} \quad$ is the index of gross investment for the ith year; and

$\mathrm{K}_{1959-60}$ is the depreciated value of the Capital Stock in 1959-1960.

From 1959-1960 onwards, cumulated gross investment is obtained by adding gross investment in each year to the cumulated gross investment up to 1959-1960. Investment indices are taken from Islam [6] and from various issues of the Foreign Trade Statistics [14]. Depreciation rates are obtained from Kemal [9]. Investment data are obtained from the Planning Commission Report [15] and $K_{1959-60}$ from Kemal [9].

In order to obtain cumulated output for the period 1959-1960 to 1969-1970, we require data on output from 1949-1950 to 1969-1970. However, data are not available for the years prior to 1954-1955. They are obtained by using linear extrapolation techniques. Data for the period 1954-1955 to 1958-1959 are taken from various issues of CMI [13] and for the period from 1959-1960 to 1969-1970 are taken from Kemal [9].

Data on cumulated gross investment and cumulated output so obtained, along with the data on value added, capital and employment, have been reported in Kemal [9], and used in this paper.

Received December, 1978; final version received February, 1979

${ }^{1}$ There was hardly any industry prior to $1949-1950$. Therefore, cumulation for 1949-1950 onwards is a fairly good indicator of the experience.

\section{REFERENCES}

1. Arrow, K. "The Economic Implications of Learning-by-Doing." Review of Economic Studies. June 1962.

2. Bardhan, J. "An Optimum Subsidy to a Learning Industry: An Aspect of the Theory of Infant Industry Protection." International Economic Review. February 1971.

3. David, P. Technical Choice, Innovation and Economic Growth. New York: Cambridge University Press. 1975.

4. Fellner, W. "Specific Interpretation of Learning-by-Doing." Journal of Economic Theory. August 1969.

5. Islam, N. "Comparative Cost, Factor Proportions and Industrial Efficiency in Pakistan." The Pakistan Development Review. Vol. IX, No. 2. Summer 1969.

6. _- Imports of Pakistan: Growth and Structure-A Statistical Study. Karachi: Pakistan Institute of Development Economics. 1967 (Statistical Paper No. 2).

7. Johnson, H.G. Aspects of the Theory of Tariff. London: Allen and Unwin. 1971.

8. Kemal, A.R. "Consistent Time Series Data Relating to Pakistan's Large Scale Manufacturing Industries.” The Pakistan Development Review. Vol. XV, No. 1. Spring 1976.

9. - - "An Analysis of Industrial Efficiency, 1959-60 to 1969-70." $\mathrm{Ph}$. D. Thesis submitted to the University of Manchester. 1978.

10. Kmenta, J. "On the Estimation of C.E.S. Production Function." International Economic Review. June 1967.

11. Lave, L. Technological Change: Its Conception and Measurement. New Jersey: Prentice Hall. 1966.

12. Naqvi, S.N.H. "Protection and Economic Development." Kyklos. Fasc. 1. 1969.

13. Pakistan. Central Statistical Office. Census of Manufacturing Industries. Karachi. (Various Issues).

14. —_. Central Statistical Office. Monthly Foreign Trade Statistics. Karachi. (Various Issues).

15. - Planning Commission. Report of the Working Group on Private Investment for the Annual Plan. Islamabad. 1973.

16. Rapping, L. "Learning and World War II Production Functions." Review of Economics and Statistics. February 1967.

17. Sheshinsky, E. "Tests of the Learning-by-Doing Hypothesis." Review of Economics and Statistics. November 1967.

18. Steedman, I. "The Implication for the Theory of the Firm of the Dependence of Current Production and Market Possibilities on Past Output and Scale." Ph. D. Thesis submitted to the University of Manchester. 1967.

19. Thomas, D. Capital Accumulation and Technological Transfer: A Comparative Analysis of Nigerian Manufacturing Industries. New York: Praeger Publishers. 1975.

20. Wright, T. "Factors Affecting the Cost of Airplanes." Journal of Aeronautical Sciences. February 1936. 